\title{
Investigation of Distress Tolerance Levels of University Students According to Different Variables
}

\author{
Öner Gülbahçe ${ }^{1}$, Arzu Gülbahçe ${ }^{1}$ \\ ${ }^{1}$ Atatürk University, Kazım Karabekir Faculty of Education, Erzurum, Turkey \\ Correspondence: Öner Gülbahçe, Atatürk University, Kazım Karabekir Faculty of Education, Erzurum, Turkey.
}

Received: December 24, 2018

Accepted: January 8, 2019

Online Published: January 9, 2019

doi:10.11114/jets.v6i12a.3962

URL: https://doi.org/10.11114/jets.v6i12a.3962

\begin{abstract}
The main aim of this research was to reveal relationship between distress tolerance levels of university students according to different variables. The study sample consisted of 600 students in 2017-2018 academic years at Ataturk University in Erzurum, Turkey. In the study the "Distress Tolerance" Scale was conducted. It was developed by Simons et al. (2005) and its verification and validation in Turkish was conducted by Sargin et al (2012). SPSS 21 package program was used to analyze the data. In the analysis of data; frequency distribution was used in determination of demographic characteristics, the Independent Samples $T$ test was used in examination of relationship between two independent variables and distress tolerance level, the one way ANOVA analysis test was used in examination of relationship between more than two variables and the distress tolerance levels. All these tests were analyzed in SPSS 21 package program and the significance was evaluated at $\mathrm{p}<0.05$ level.

According to the findings, it was determined that there was a significant difference between the students' distress tolerance levels and sports activity. It was observed that the students who were doing sports activities have higher distress tolerance level than those were not doing sportive activities. No significant difference was found between the distress tolerance level and gender, grade level and family structure.

As a result of the fact that sports activities have a positive effect on the distress tolerance level, it is recommended that students be given opportunity to make different sports activities, by raising their awareness about the sports activity in order to increase the distress tolerance in learning process or the course of life However, it is also recommended to carry out studies to identify different variables that may have an impact on distress tolerance.
\end{abstract}

Keywords; distress tolerance, distress tolerance of university students, sports and distress tolerance

\section{Introduction}

Distress is characterized by negative emotions and it is events and phenomena that force the individual psychologically. Psychological distress is defined as the consequences of factors such as psychogenic pain, internal conflict, and stress caused by the environment, which prevent people from self-actualization and establishing healthy relationships with others. Although distress is the result of a psychomotor process, it exposes as an emotional and touching situations. Distress tolerance includes all emotional states and it refers whether they can be controlled or not. In particular, it is defined as the experience of negative psychological states and emotions and the ability to tolerate and endure these situations. Therefore, it should not be confused with the ability to withstand discomfort which is related to ability to withstand negative events and facts (Simons and Gaher, 2005).

Simons and Gaher (2005) defined distress as a high level emotional structure that includes expectations and evaluations about experiencing an emotional situation that affects the individual negatively. Four different dimensions were determined within this structure.

\section{$\begin{array}{lll}\text { 1. Endurance } & \text { 2. Evaluation - acceptability } \quad 3 . \text { Organizing emotions } \quad 4 \text {. Focusing on distress. }\end{array}$}

From this framework; when the individual encounters an unfavorable situation and have insufficient capacity to tolerate distress it is expected that he/she cannot tolerate the situation. Then, the individual considers the process as being in trouble, but may have difficulties in accepting that situation. Being embarrassed or the feeling of being inability to overcome to the distress have important place in the inability to accept the distress. The next step is to reduce the distress or to try avoiding the feeling of distress. These efforts are often the result of sudden decisions and often include 
short-term solutions. Finally, when the reduction of avoidance from distress is not successful, the distress takes attention and energy of the person by covering a significant part of his/her life. So, life routine be affected and the functionality be impaired as a result of focusing on the negative emotions. It is expressed that once people with inadequate capacity deal with distress, instead of researching a solution, focus on the negative emotions they felt and experience distress situations and make an effort to reduce negative feelings (Simons and Gaher, 2005, cited in Udum, 2018). Psychologically resistant individuals can successfully fight with problems, adapt into difficult life process and have personal power to achieve that. Psychologically resistant individuals, who are successful in socialization and communication, do not feel difficulty to establish healthy relations with the environment. They have problem solving skills and have sufficient power for self-development and self- renewal. Their social life is mobile. They participate in different activities and are confident. And they turn their sorrow and distress into favor (Çakar et al. 2014).

Decker (1997), Burnette and Mui (1997) conceptualize psychological distress as the desire, enthusiasm, lack of excitement, sleep disturbance, demoralization, lack of courage, hopelessness for future, being overly emotional, feeling bored, idea of distraction and suicidal tendency (Decker 1997; Burnette and Mui 1997; Weayer and Clum 1995). Chalfant et al. (1990) describe psychological distress as unhappiness, irritability, restlessness, and chaining of problems in human relationships (Chalfant et.al. 1990).

University youth are the most dynamic element of socio-cultural structure of the society. The most important difference that distinguishes university youth from other youth categories is that they are knowledgeable, educative, executive and decision-making candidates of the future. In this respect, young university students have responsibility of being helpful to society while planning their future. During university education process, the problems such as housing and food problems, opportunities to fill free time, financial issues, being at different socio-economic level, problems encountered during exams, exhaustion caused by overwork, difficulties in establishing male-female friendship, interpersonal relations, feelings and anxiety disorders, adaptation problem, longing for family and motherland, dependence on parents, academic and professional problems, and problems in terms of social cohesion make youth to experience distress in different ways and these problems affect their success levels negatively (www.hugam.hacettepe.edu.tr. 2015; Kutlu, 2004).

According to Özgüven (1992), university life in Turkey, as well as other countries, generally bears features of an environment that produces anxiety and stress. University student is an individual with personal and development problems. University student is neither adult nor a child. It carries problems rooted in transition period from childhood to adulthood (Demir and Koydemir, 2005; Özgüven, 1992).

Sports or practicing physical activity is one of the effective ways to cope with stress and distress. Doing sports triggers feeling of happiness through hormones, employs mind and removes negative thoughts from it. Walking, jogging or doing any sports activities are some of the effective ways to relax individuals who are experiencing extreme stress (Pervin, 2018).

Sports is a social phenomenon that has made individuals dependent on it directly or indirectly and has always managed to keep people's interest alive in many different ways in social life. Sports, which attach people to itself by satisfying their needs with indispensable tastes, has developed particular ideas, beliefs and symbols that are very close to society by imposing that it is a big social institution in today's world. The rapidly developing technology in the modern world has gradually reduced the need for manpower. As a result, a life style that does not conform to the natural structure of man, along with pressures and stresses from the work and social environment, push people into distress at a psychological level. At this stage, people can both develop themselves psycho-socially and stay away from stress and distress with the help of relaxing and monotony-saving function of sports activities (Küçük and Koç, 2003). In this respect, this study was conducted considering that sports activities may affect university students' distress tolerance level. So, the aim of this study was to investigate the university students' distress tolerance in terms of sports activities and different variables. On the other hand, it aimed to examine whether there is a difference between students' distress tolerance levels and gender, grade level, family structure and sports activity.

\section{Method}

The study is a descriptive study of relational screening model. This model is often used to determine the interaction and quantity between two or more variables. Relational screening model, which does not give a real cause-effect relation, allows estimation of the situation in other variable or variables in accordance with the information of a particular variable (Büyüköztürk et. al. 2014).

\subsection{Participants}

The study sample consists of 600 students in 2017-2018 academic years at Ataturk University in Erzurum, Turkey. The independent variables used in the study were determined by the personal information form prepared by the researchers. 


\subsection{Data Collection Tools}

In the study the "Distress Tolerance" Scale was used. It was developed by Simons et al. (2005) and its verification and validation in Turkish was made by Sargin et al (2012). The Distress Tolerance Scale (DTS) is a 5-point Likert-type scale with 15 items. The participant answers the questions of 5-point Likert ("I don't agree at all," "I disagree", "Neither agree nor disagree", "I agree," "I totally agree"). The Turkish standardization study of the Distress Tolerance Scale, which was developed by Simons and Gaher in 2005, was made by Sargin et al in 2012. There are three subscales in the Turkish form; tolerance (items 1, 2, 3, 4, 5, 10, 11, 12 and 15), regulation (items 8, 13 and 14) and self-sufficiency (items 6, 7 and 9). When the results are calculated, a single score gives an idea about the person's capacity to tolerate distress. The higher score refers to higher distress tolerance capacity. Cronbach's alpha coefficient of internal consistency was found to be 0.89 (Sargin et al., 2012; Udum, 2018). Total score was taken into consideration in this study.

\subsection{Data Analysis}

In the analysis of the data, the frequency distribution was applied to determine demographic characteristics and sports activities, the Independent Samples T test was applied to determine relationship between two independent variables and distress tolerance level and the One Way Anova analysis tests were applied to examine relationship between more than two variables and distress tolerance level. All these tests were analyzed in SPSS 21 package program and the significance level was taken as $\mathrm{p}<0,05$. In the validity and reliability analysis, Alpha value was found to be 0.806 .

\section{Results}

In this section, the frequency distributions of demographic characteristics and sportive situation of the students and the statistical tables of these variables and distress tolerance levels are presented.

Table 1. Demographic Characteristics of the Students

\begin{tabular}{|c|c|c|c|}
\hline \multicolumn{2}{|c|}{ Variable } & $\mathbf{N}$ & $\%$ \\
\hline \multirow{3}{*}{ Gender } & Female & 408 & 68,0 \\
\hline & Male & 192 & 32,0 \\
\hline & Total & 600 & 100,0 \\
\hline \multirow{4}{*}{ Grade Level } & 1st Grade & 153 & 25,5 \\
\hline & 2nd Grade & 198 & 33,0 \\
\hline & 3rd Grade & 146 & 24,3 \\
\hline & 4th Grade & 103 & 17,2 \\
\hline \multirow{3}{*}{ Family Structure } & Nuclear family & 462 & 77,0 \\
\hline & Extended family & 124 & 20,7 \\
\hline & Separated family & 14 & 2,3 \\
\hline
\end{tabular}

The study was conducted on a total of 600 students (408 females and 192 males). It consists of students mainly in a nuclear family structure, with a same average distribution in different grades.

Table 2. Distribution of Sports Activity Status of the Students

\begin{tabular}{cccc}
\hline & Variable & $\mathbf{N}$ & $\mathbf{\%}$ \\
\hline Sports Activity & Yes & 220 & 36,7 \\
Status & No & 380 & 63,3 \\
& Total & 600 & 100,0 \\
Sports Activity & Individual sports & 151 & 25,2 \\
Type & Team sports & 35 & 5,8 \\
& Both & 34 & 5,7 \\
& I am not doing sports & 380 & 63,3 \\
Weekly Sports & Less than 1 hour & 68 & 11,3 \\
Time & Between 2 - 3 hours & 81 & 13,5 \\
& Between 4 - 5 hours & 38 & 6,3 \\
& 6 hours or more & 33 & 5,5 \\
Purpose of Doing & Not doing sports & 380 & 63,3 \\
Sports & Health & 130 & 21,7 \\
& Social environment & 19 & 3,2 \\
& Economic gains & 16 & 2,7 \\
& Social activity & 55 & 9,2 \\
& Not doing sports & 380 & 63,3 \\
\hline
\end{tabular}

The sports activity status of the students shows that 220 students were doing sports activities and 380 students were not doing sports activities. It was observed that the students engaged in sports activities mainly engaged in individual sports 
activities and the majority of them performed it for 2-3 hours. The students engaged in sports activities stated that they were doing sports for the purpose of health.

Table 3. Results of the $t$ test analysis of Gender and Distress Tolerance Level

\begin{tabular}{|c|c|c|c|c|c|c|c|}
\hline & & Gender & $\mathbf{N}$ & $\mathbf{X}$ & SS & $\mathbf{T}$ & $\mathbf{P}$ \\
\hline \multirow{2}{*}{$\begin{array}{l}\text { Distress } \\
\text { Level }\end{array}$} & \multirow[t]{2}{*}{ Tolerance } & Female & 408 & 47.3676 & 9.46283 & \multirow{2}{*}{1.231} & \multirow{2}{*}{.219} \\
\hline & & Male & 192 & 48.3505 & 8.95337 & & \\
\hline
\end{tabular}

Considering the total score averages of the students with respect to their gender and distress tolerance scale according to the significance level of $p<0.50$ no significant difference was found. It was also observed that the total score of distress tolerance of males is higher than females.

Table 4. Results of the $t$ test analysis of Grade Levels and Distress Tolerance Level

\begin{tabular}{cccccc}
\hline Grade Level & N & X & SS & F & P \\
\hline 1st Grade & 153 & 47.1634 & 9.32206 & & \\
2nd Grade & 198 & 47.6263 & 9.41711 & & \\
3rd Grade & 146 & 47.8171 & 9.58296 & .357 & .784 \\
4th Grade & 103 & 48.3689 & 8.74137 & & \\
Total & 600 & 47.6822 & 9.30669 & &
\end{tabular}

In terms of the total score averages of the grade level and distress tolerance scale of the students according to the significance level of $\mathrm{p}<0.50$ no significant difference was found. It was observed that distress tolerance level increases in parallel with increase in grade level.

Table 5. Results of the ANOVA test analysis of Family Structure and Distress Tolerance Level

\begin{tabular}{cccccc}
\hline Family Structure & $\mathbf{N}$ & $\mathbf{X}$ & SS & $\mathbf{F}$ & $\mathbf{P}$ \\
\hline Nuclear family & 462 & 47.6753 & 9.14540 & & \\
Extended family & 124 & 47.7363 & 9.85342 & .007 & .993 \\
Separated family & 14 & 47.4286 & 10.30843 & & \\
Total & 600 & 47.6822 & 9.30669 & &
\end{tabular}

Considering the total score averages of family structures and distress tolerance scale according to the significance level of $\mathrm{p}<0.50$ no significant difference was found.

Table 6. Results of the $t$ test analysis of Sports Activity Status and Distress Tolerance Level

\begin{tabular}{ccccccc}
\hline & Sports Activity Status & N & X & SS & t & P \\
\hline Distress & Yes & 220 & 49.4968 & 9.00172 & & \\
$\begin{array}{c}\text { Tolerance } \\
\text { Level }\end{array}$ & No & 380 & 46.6316 & 9.33013 & 3.707 & .000 \\
\hline
\end{tabular}

In terms of the total score averages of sports activity status and the tolerance distress scale were examined according to the significance level of $\mathrm{p}<0.50$ a significant difference was found. It was observed that distress tolerance of students doing sports activities is higher than the students not doing sports activities.

Table 7. Results of the ANOVA test analysis of Sports Activity Type and Distress Tolerance Level

\begin{tabular}{ccccccc}
\hline $\begin{array}{c}\text { Sports Activity } \\
\text { Type }\end{array}$ & $\mathbf{N}$ & $\mathbf{X}$ & $\mathbf{S S}$ & $\mathbf{F}$ & $\mathbf{P}$ & Difference \\
\hline Individual sports & 151 & 49.1344 & 9.25144 & & & \\
Team sports & 35 & 52.0857 & 7.34996 & & & \\
Both & 34 & 48.4412 & 9.17570 & 5.656 & .005 & $1>4$ \\
Not doing sports & 380 & 46.6316 & 9.33013 & & .001 & $2>4$ \\
Total & 600 & 47.6822 & 9.30669 & & & \\
\hline
\end{tabular}


Considering the total score averages of distress tolerance of the sports activity type and not doing sports according to the significance level of $p<0.50$ a significant difference was found. It was observed that students doing individual sports and team sports have higher distress tolerance level than those are not doing sportive activities. No significant difference was found between sports activity types.

Table 8. Results of the ANOVA test analysis of Weekly Sports Time and Distress Tolerance Level

\begin{tabular}{ccccccc}
\hline Sports time hours/week & $\mathbf{N}$ & $\mathbf{X}$ & $\mathbf{S S}$ & $\mathbf{F}$ & $\mathbf{P}$ & Difference \\
\hline Less than 1 hour 1 & 68 & 48.8382 & 8.86147 & & & \\
Between 2 - 3 hours 2 & 81 & 48.9667 & 9.65272 & &, 039 & $5<2$ \\
Between 4 - 5 hours 3 & 38 & 50.6842 & 8.95063 & 3,837 &, 010 & $5<3$ \\
6 hours or more 4 & 33 & 50.7879 & 7.71669 & &, 013 & $5<4$ \\
Not doing sports 5 & 380 & 46.6316 & 9.33013 & & & \\
Total & 600 & 47.6822 & 9.30669 & & &
\end{tabular}

Considering the total score averages of distress tolerance of the sports time of the students doing sports and not doing sports according to the significance level $p<, 050$ a significant difference was found. It was observed that the students who were not doing sports activities have lower distress tolerance levels than those who were doing sports activities 2-3 hours, 4-5 hours and 6 hours or more in a week. There was found no significant difference between sports activity time.

Table 9. Results of the ANOVA test analysis of Purpose of Doing Sports and Distress Tolerance Level

\begin{tabular}{ccccccc}
\hline $\begin{array}{c}\text { Purpose of Doing } \\
\text { Sports }\end{array}$ & N & $\mathbf{X}$ & SS & F & P & Difference \\
\hline Health 1 & 130 & 49.9923 & 8.89952 & & & \\
Social environment 2 & 19 & 49.7368 & 12.14652 & & & \\
Economic gains 3 & 16 & 50.7063 & 6.26902 & 3.950 & .000 & $1>5$ \\
Social activity 4 & 55 & 47.8909 & 8.69796 & & & \\
Not doing sports 5 & 380 & 46.6316 & 9.33013 & & & \\
Total & 600 & 47.6822 & 9.30669 & & & \\
\hline
\end{tabular}

Considering the total score averages of distress tolerance of aims of students who were doing sports activities and not doing sports activities according to the significance level $p<0.50$ a significant difference was found. It was observed that students who were not doing sports activities have lower distress tolerance level than those doing sports with purpose of health. No significant difference was found between the sports activities.

\section{Discussion and Conclusion}

In the study, it was found that there was no significant difference between gender and distress tolerance levels of the students. The related literature shows that there are similar studies supporting the findings of the research. Çiftçi (2002) did not find a significant relationship between gender factor and distress tolerance level of adolescents in his study about relationship between stress coping and stress tolerance. Çebi (2009) examined attitudes of university students about receiving psychological support and did not find a significant relationship between gender and psychological distress and attitudes towards getting psychological support.

It was also found that there was no significant difference between grade level and distress tolerance level of the students. In the study conducted by Güngör (2008) which is entitled "The Effects of Emotional Intelligence on Psychological Distress Symptoms in University Students," no significant difference was found according to grade level. In addition, Doğan and Eser (2013) and Yurtsever (2009) did not find a significant difference in their study on coping strategies of university students.

It was determined that there was no significant difference between family structures and distress tolerance levels of the students. However, in his study, Güngör (2008) stated that students whose family type is the core large family have higher tolerance to stress than those whose family type is fragmented. It can be stated that mother, father and children in a nuclear family are aware of the difficulties encountered because of closer relations between them. And they can easily eliminate the problems experienced because they support each other. However, as family expands, it is possible to observe a decrease in interaction between parents and children (Gander and Gardiner, 2007).

Considering the sports activity status of the students and distress tolerance levels, a significant difference was found. It 
was observed that distress tolerance level of the students doing sports activities is higher than the students not doing sports activities. Şar (2016) also found that the psychological tolerance levels of individuals doing sports have a higher average than those were not. This finding is in line with the results of the current research.

Considering sports activity type and distress tolerance level of the students, a significant difference was found. It was observed that the students doing individual and team sports have higher distress tolerance level than those were not doing sports. In a study conducted by Salar, Hekim and Tokgöz (2012), it was determined that athletes who were interested in individual or team sports branches at least 3-4 days regularly a week feel themselves emotionally better and have a higher psychological tolerance level. This finding, which is parallel to the results of the current study, shows that it is an important factor to increase the distress tolerance of the youth whether they were doing individual or team sports. It is an expected result that young people who are able to make independent decisions and have confidence in individual sports and share responsibility and help in team sports have high distress tolerance levels.

In terms of sports activity levels and distress tolerance levels of the students, it was determined that there was a significant difference. It was observed that the students who were not doing sports activities have lower distress tolerance levels than those who are doing sports activities between 2-3 hours, 4-5 hours and 6 hours or more. Yurtsever (2009) also stated that students doing regular sports know better ways of coping with stress and distress compared to the students who were not doing or infrequently doing sports. They also reduced sympathetic system problems based on stress. This result shows a parallelism with the results of the current study and indicates that sporting activity is an important factor in making university students more resilient to their problems.

Considering students' purpose of doing sports activity and distress tolerance level, it was determined that there was a significant difference. It was observed that students who were not doing sports activities have lower distress tolerance level than those who were doing sports with purpose of health. The benefits of sports to both physical and mental health are well known. Individual cannot remove stress and distressing events from his life completely. However, by doing sports and exercise in order to be healthy it is possible to move away from stress and become more tolerant to distress.

It is a fact that young people experience different problems and difficulties during university years, which are considered to be one of the most beautiful periods of their life. In this process, universities have great responsibilities in reducing problems experienced by students. It is necessary to make psychological counseling and guidance services effective in order to identify problems rooted in university, personal-social, educational or professional areas and solve them as much as possible. It is necessary to make researches that determine problems experienced by young people with different time intervals and to support students by increasing the number and variety of sports activities that considered being helpful in reducing distress. Sports activities, which can be done individually or in a team in accordance with interest and ability of young people, will be helpful to get away from problems and feel better.

\section{References}

Aydın, B., \& İmamoğlu, S. (2001). Group Work for Developing Coping Skills with Stress, MU Atatürk Education Faculty, Journal of Educational Sciences, 14, 41-52.

Burnette, D., \& Mui, A. (1997). Correlates of Psychological Distress among Old-Old Hispanics, Journal of Clinical Geropsychology, 3, 227-244.

Büyüköztürk, Ş., Çakmak, E., Akgün, Ö., Karadeniz, Ş., \& Demirel, F. (2014). Scientific research methods, Ankara: Pegem Publications.

Çakar, S. F., Karataş, Z., \& Çakır, M. A. (2014). Adult Resilience Scale: Adaptation to Turkish Culture. Mehmet Akif Ersoy University Faculty of Education Journal, 32, 22-39.

Çebi, E. (2009). University Students' Attitudes towards Psychological Help: Perceived Social Support, Psychological Distress, Helping Experience and Gender Effect. Master's Thesis. Middle Eastern Technical University/ Social Sciences Institute/ Department of Educational Sciences. Ankara.

Chalfant, H. P. et al. (1990). The Clergy as a Resource for Those Encountering Psychological Distress. Review of Religious Research. 31(3), 305-313.

Çiftçi, M. P. (2002). Investigation of the Relationship between Resistance to Stress and aof High School Students. Group of High School Students' Ways of Coping with Stress. Unpublished Master's Thesis. İzmir: Dokuz Eylül University, Educational Sciences Institute.

Decker, F. H. (1997). Occupational and Non-occupational Factors in Job Satisfaction and Psychological Distress Among Nurses. Research in Nursing \& Health, 20(5), 453-464.

https://doi.org/10.1002/(SICI)1098-240X(199710)20:5<453::AID-NUR9>3.0.CO;2-N

Demir, A., \& Koydemir, S. (2005). Help Seeking Behavior in METU Students. VIII. National Psychological Counseling 
and Guidance Congress, Marmara University, Istanbul.

Doğan, B., \& Eser, M. (2013). Stress Coping Methods of University Students. Electronic Journal of Vocational Colleges, 3(4), 29-39.

Gander, M. J., \& Gardiner, H. W. (2007). Child and Adolescent Development, Ankara: Imag Bookstore.

Güngör, M. (2008). Psychological Abuse in Working Life. İstanbul: Derin Publication.

Küçük, V., \& Koç, H. (2003). The relationship between human and sport in the process of psycho - social development. Dumlupinar University, Journal of Social Sciences, 2(4), 14-19.

Kutlu, M. (2004). The Problems and Expectations of the University Students Regarding to practice Orientation Services, XIII. National Educational Sciences Congress, 6-9 July, Malatya.

Özgüven, İ. E. (1992). The Problems of University Students and the Ways of Coping with them. Journal of Faculty of Education, 7, 5-13.

Pervin, D. (2018). Health News. How Stress Causes, How is it Treated? 08 August 2018.

Salar, B., Hekim, M., \& Tokgöz, M. (2012). The Comparison of Emotional Situations of 15-18 Age Group Teams and Individuals. Mehmet Akif Ersoy University Journal of the Institute of Social Sciences, 4(6), 123-135.

Sargın, A. E., Özdel, K., Utku, Ç., Kuru, E., Yalçınkaya-Alkar, Ö., \& Türkçapar, M. H. (2012). Validity Reliability Study of Distress Tolerance Scale, Journal of Cognitive Behavioral Psychotherapy and Research, 1(3), $152-161$.

Simons, J. S., \& Gaher, R. M. (2005). The Distress Tolerance Scale: Development and Validation of A Self-Report Measure, Motivation and Emotion, 29(2), 83-102.

Şar, N. Ş. (2016). Psychological Endurance and Personality Traits of Individuals Who Do Sports and Do Not. Master Thesis, Sakarya University, Institute of Educational Sciences, Sakarya.

Udum, S. (2018). Investigation of the Relationship between Distress Tolerance and Use of Drug, Master's Thesis. Hasan Kalyoncu University Social Sciences Institute, Department of Psychology, Clinical Psychology Master's Program. Gaziantep.

Weaver, T. L., \& Clum, G. A. (1995). Psychological Distress Associated with Interpersonal Violence: A Meta-Analysis, Clinical Psychology Review, 15(2), 115-140.

Yurtsever, H. (2009). Effects of Personality Characteristics on Stress Level and Ways to Cope with Stress: A Research on University Students, Master's Thesis. Dokuz Eylül University, Social Sciences Institute Department of Department of Labor Economics and Industrial Relations. Human Resources Program. İzmir.

\section{Copyrights}

Copyright for this article is retained by the author(s), with first publication rights granted to the journal.

This is an open-access article distributed under the terms and conditions of the Creative Commons Attribution license which permits unrestricted use, distribution, and reproduction in any medium, provided the original work is properly cited. 